period before you purchase a handgun. Rifle and shotgun controls are barely on the agenda.

There is a much lauded victory that saw military assault weapons banned. But let's read that again: newly manufactured assault weapons are banned, but not the hundreds of thousands of second-hand machine guns that can be openly traded with no gun register to track them, nor the tens of thousands that were stockpiled by gun dealers when they were given many months forewarning of the ban.

Last week I went to a sporting goods store in Virginia, some $10 \mathrm{~km}$ from the heart of Washington DC. It was the size of an aircraft hangar. The place teemed with families buying joggers, rollerblades, and baseball gear. As natural as apple pie, an entire wall of the store was covered with rifles and shotguns, with a glass counter that ran about 20 metres filled with handguns. The American who took me there said with a straight face "Virginia has introduced very strict new gun laws-you can only buy one handgun a month."

The National Rifle Association has a slogan "Guns don't kill people. People kill people" to which Handgun Control replies “Guns don't die. People do.” American media parochialism shields most Americans from realising that the home-as-fortress mentality they live under is not normal. Thank heavens Australia's openness to the world allowed us enlightenment enough to read the sign "Go back-you're going the wrong way."

SC is a spokesperson for the Coalition for Gun Control.

1 Centers for Disease Control. Deaths resulting from firearm- and motor-vehicle-related injuries - United States, 1968-1991. MMWR 1994;43:37-42.

2 Fingerhut $\mathrm{L}$, Jones C, Makuc D. Firearm and motor vehicle injury mortality - variations by State, race and ethnicity: United States, 1990-91. Advance data from vital and health statistics. No 242. Hyatsville, Maryland: National Center for Health Statistics, 1994.

3 Annest JL, Mercy JA, Gibson DR, Ryan GW. National estimates of nonfatal firearm-related injuries: beyond the tip of the iceberg. $\mathscr{Y} A M A$ 1995;273:1749-54.

4 Violence Policy Center. More gun dealers than gas stations. A study of federally licensed firearms dealers in America. Washington DC: Violence Policy Center, 1992.

5 Sugarmann J. Number of gun dealers plummets by 100,000 in two years [press release]. Washington DC: Violence Policy Center, 15 May, 1996.

6 Pierre RE. Recent slayings send D.C. toll to 253. Washington Post 1996;20 Aug:B3.

7 Kleck G. Point blank: guns and violence in America. Hawthorne, NY: Aldine, 1991.

(Accepted 5 September 1996)

\title{
Care of Older People
}

\section{Community care: the independent sector}

\section{S Barodawala}

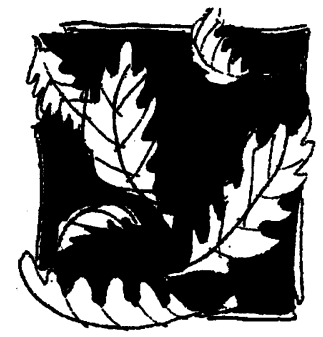

This is the 11th in a series of 14 articles edited by Eileen Burns, Neil Penn, and Graham Mulley

St James's University Hospital, Leeds LS9 7TF $S$ Barodawala, registrar in medicine for the elderly
The independent sector, which consists of the voluntary and private sectors, is a vital element in supporting older people in the community. The voluntary sector, coordinated by the Council for Voluntary Service and the National Council for Voluntary Organisations, provides a variety of services, including practical help, reassurance and companionship, and advice, information, campaigning, and advocacy. The private sector owns all of the nursing homes and most of the residential homes and is gradually becoming more involved with the provision of services to help support older people in their own homes. With this increase in size and importance of the independent sector over recent years, there is now a real need for greater communication between the private, voluntary, and statutory agencies in any one region. In some areas, forums made up of representatives of these various sectors meet to discuss relevant issues and construct local policies, thus allowing a more coordinated approach to the delivery of services.

Over the past 20 years the emphasis on supporting older people has shifted from institutional care to care in the community, which is provided in combination by the social services department, the voluntary and private sectors, and informal groups.

Since the implementation of the Community Care Act in 1993, the needs of older people and their carers are now formally assessed; ideally, suitable services are then provided. These reforms have meant that voluntary and private organisations are now increasingly being asked to provide residential care, day care, and home based services under contract to social services departments.

\section{The voluntary sector}

The role of the voluntary sector in society is becoming ever more important. Voluntary organisations vary tremendously from large, national organisations with paid staff, to small, local charities providing advocacy, self help, and specific services to communities. Also, as

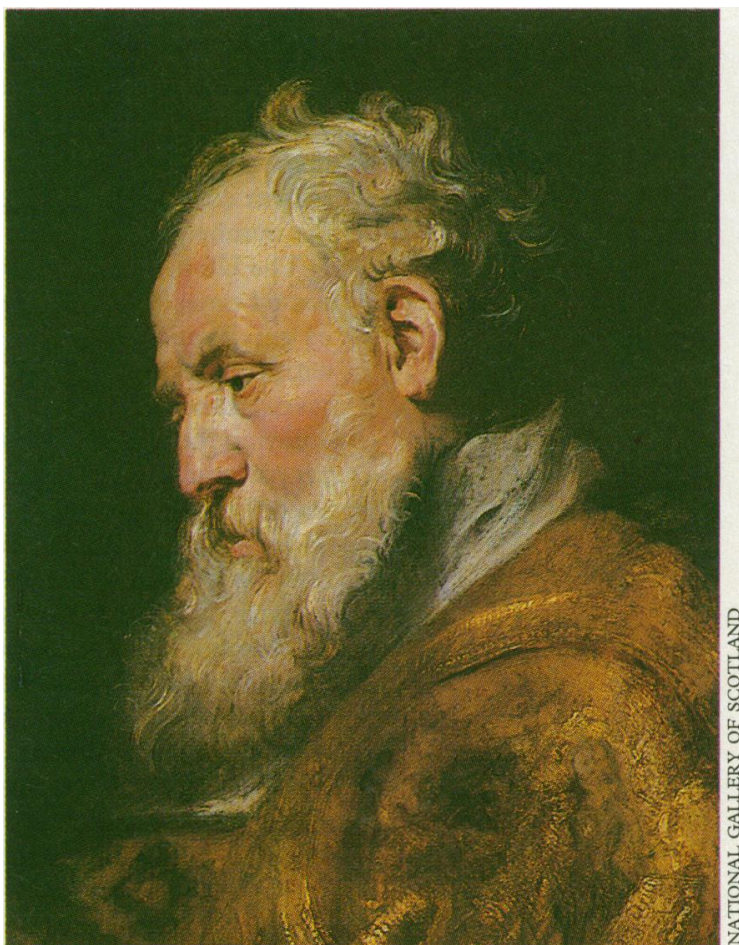

"Study of a head (St Ambrose)" by Sir Peter Paul Rubens $(1577-1640)$ 
needs and resources differ regionally, the services available vary from locality to locality. Despite this diversity, all voluntary groups share the philosophy that no person should suffer oppression or lack of opportunity because of race, gender, belief, sexuality, disability, age, class, or geographical location, and that local voluntary and community action is a means of combating disadvantage and contributes to the quality of life for groups, communities, and individuals in local areas.

\section{Coordinating voluntary organisations}

As the role of the voluntary sector in society grows and becomes ever more complex, it no longer makes sense for the voluntary organisations to work in isolation. Two organisations work with voluntary groups, at national and local levels, providing help and support and promoting their work. They also provide a vital link with the statutory authorities, which is important for planning services in a specific area.

Council for Voluntary Service-The CVS is itself a voluntary organisation. It works with other voluntary groups in a local area, helping to coordinate the existing services they provide and to develop new services as required. It also provides information to the general public, health professionals, statutory departments, and other voluntary organisations. Local branches are given in the Yellow Pages or can be obtained from the National Association of Councils for Voluntary Service (address below).

National Council for Voluntary Organisations-The NCVO is the representative body for the voluntary sector in England. It brings voluntary organisations together so that they can work together, learn from each other, maximise scarce resources, and make their voice heard.

\section{Addresses of national organisations}

National Association of Councils for Voluntary Service (NACVS), 3rd floor, Arundel Court, 177 Arundel Street, Sheffield S1 2NU (tel 0114278 6636)

National Council for Voluntary Organisations, Regents Wharfe, 8 All Saints Street, London N1 9RL (tel 01717136161 )

\section{Blanket organisations}

Some voluntary organisations-such as Age Concern and Help the Aged-are concerned with the overall issues of old age. They campaign for the interests of older people, research into their needs, and provide local and national services to help elderly people. They have also become important in raising public awareness of the challenges of aging and in furthering educational activities.

Age Concern has been working for over 50 years to ensure that older people get the support, encouragement, and care they require. This is achieved through a network of 100 national organisations and over 1400 local Age Concern schemes. The schemes provide practical help at a local level in the form of day centres, hospital aftercare, advocacy, and insurance schemes. Age Concern England supports this work through fund raising, training, campaigning, research, the provision of information, and publishing.

Help the Aged works to improve the quality of life of older people in the United Kingdom and internationally. It does this through information provision; fund raising and campaigning for the rights of older people; practical help at a local level, such as the provision of day centres, community transport, home safety, and community alarms; and its free national information service, Senior Line (tel 0800 289404).

\section{Addresses of blanket organisations}

Age Concern England, Astral House, 1268 London Road, London SW16 4ER (tel 0181679 8000)

Help the Aged, St James's Walk, London EC1R OBE (tel 01712530253 )

\section{Specific organisations}

DISABILITIES ASSOCIATED WITH OLD AGE

The Alzheimer's Disease Society was founded to give advice and support to those looking after someone with any form of dementia. There are over 200 local branches and support groups. The society also promotes research into the disease and lobbies at national and local level on the behalf of sufferers and their carers.

The Stroke Association, together with its Scottish sister organisation, The Chest, Heart and Stroke Association, is concerned with stroke victims and their families. It promotes research, health education, rehabilitation, and advisory and welfare services. The Stroke Association Volunteer Service provides home visiting and group meetings; its main aim is to help dysphasic stroke patients attain maximum possible recovery and become as independent as possible. The Stroke Family Support Service is a visiting service for all stroke victims, and it can refer patients to more specialised sources, such as a disabled living centre, other voluntary agencies, or local stroke clubs. Referrals to the support service can be made via hospital, the general practitioner, a social worker, or by self referral.

The Parkinson's Disease Society has more than 200 local branches. Nationally, most of its work consists of information provision, medical research, and promoting the welfare of patients with Parkinson's disease. The local branches offer opportunities for mutual support, social activities, fund raising, and practical help.

Arthritis Care is the British national welfare organisation for sufferers from arthritis. It aims to help sufferers by providing information, advice, and practical aid. Arthritis Care also has holiday centres equipped with ramps, rails, and many other facilities to increase the independence and enjoyment of disabled people.

The Royal National Institute for the Blind (RNIB) is a large organisation providing help and guidance to people who are registered as blind or partially sighted. Cur-

\section{Addresses of disability related organisations}

Alzheimer's Disease Society, Gordon House, 10 Greencoat Place, London SW1P 1PH (tel 01713060606 )

Stroke Association, CHSA House, Whitecross Street, London EC1Y 8JJ (tel 0171490 7999)

Parkinson's Disease Society, 22 Upper Woburn Place, London WC1H ORA (tel 0171388 5798)

Arthritis Care, 18 Stephenson's Way, London NW1 2HD (tel 0171916 1500)

Royal National Institute for the Blind (RNIB) 224 Great Portland Street, London W1N 6AA (tel 0171388 1266)

Royal National Institute for Deaf People (RNID), 19-23 Featherstone Street, London EC1Y 8GL (te 01712968000 )

Royal Association for Disability and Rehabilitation (RADAR), 12 City Forum, 250 City Road, London EC1V 8AF (tel 01712503222 )

Disablement Information and Advice Line (DIAI UK), Park Lodge, St Catherine's Hospital, Tick Hill Road, Doncaster DN4 8QN (tel 01302 310123) 
rently, 1 in 7 of people aged 75 and over is blind or partially sighted. It has a talking book service, a weekly newspaper-Big Print-a housing advisory service, leisure activities, residential care, and hotels. Products to help with everyday living, such as easy to see watches and clocks, kitchen equipment, and white canes, are available by post.

The Royal National Institute for Deaf People (RNID) represents deaf, hard of hearing, and deaf-blind people. Its services include information, residential care, a tinnitus help line, and providing helpful devices such as TV listening devices, flashing doorbells, and alarm clocks. The national telephone relay service, Typetalk, enables deaf people to communicate with hearing people over the telephone network.

The Royal Association for Disability and Rehabilitation (RADAR) offers advice and assistance on a variety of issues affecting people with physical disabilities-housing, aids and adaptations, access, and holidays and leisure.

The Disablement Information and Advice Line (DIAL UK) provides information and advice on a wide range of issues affecting people with disabilities and their carers.

Disabled living centres provide education and information to disabled people who require technical aids. There are more than 20 such centres around Britain. Visitors are given advice on equipment and the opportunity to try it out, costings, and details of where aids can be obtained. The address of the nearest centre can be obtained from DIAL UK.

\section{ORGANISATIONS FOR CARERS}

Only in recent years have voluntary organisations and social service departments begun to consider the needs of carers in planning provision. Currently, over six million people in the United Kingdom are looking after a disabled friend or relative at home. Doing this day in, day out can cause tremendous stress, particularly if the whole burden of responsibility falls on the carer. In these circumstances carers frequently feel isolated or become ill. There are several organisations whose primary aim is to provide practical help to caregivers.

Crossroads-The Crossroads organisation began in 1974. There are over 200 branches nationwide in the UK. The schemes are developed in partnership with local health and social services departments to ensure that they complement existing services. Crossroads services are tailored to meet the needs of the individual carer and family: each trained care attendant takes over

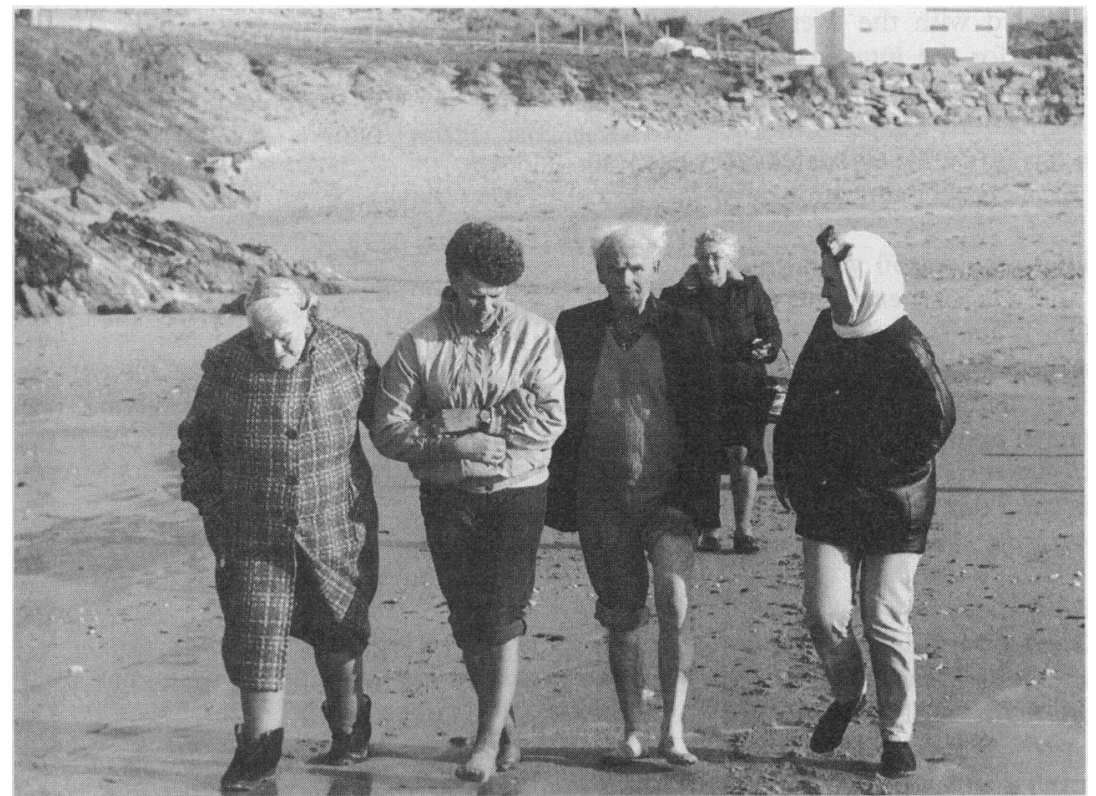

Several charities organise holidays for older or disabled people, or give grants for holidays; the Holiday Care Service coordinates such information for disabled or disadvantaged people the role of the main family carer in the home setting. Crossroads also provides respite care, carer support groups, and a carer helpline. The service is available 24 hours a day and 365 days a year.

The Carers National Association is another large organisation providing help and advice for carers. It produces a monthly magazine and has a training unit as well as other services.

\section{Addresses of organisations for carers}

Crossroads Scheme, 3rd Floor, Dilke House, Malet Street, London WC1E 7JA (tel 0171637 1855)

Carers National Association, 20/25 Glasshouse Yard, London EC1A 4JS (carers helpline: tel $01714908898)$

\section{ASSOCIATIONS WITH LOCAL FOCUS}

Organisations with a local focus are extremely valuable within each community. Their telephone numbers can be obtained from the Yellow Pages or the local branch of the Council for Voluntary Service.

- Women's Royal Voluntary Service (WRVS)

- Citizens Advice Bureau

- Neighbourhood schemes

- Community based day centres and luncheon clubs.

ORGANISATIONS WITH CULTURAL OR RELIGIOUS THEMES

With the increase in numbers of elderly people from ethnic minorities living in British communities, there is a great need for organisations to provide the specialised care and support they require.

- Jewish Welfare Board

- Asian People with Disabilities Alliance

- Black Elders Associations

OTHER SERVICES AVAILABLE THROUGH THE VOLUNTARY SECTOR

Gardening and other jobs around the house-Some of the smaller, more locally based voluntary organisations may be able to provide services such as gardening and decorating for older people who are not able to do these tasks themselves. They usually charge only for materials used. Details may be available from the local Council for Voluntary Service.

Domiciliary visiting schemes-Many organisations run visiting schemes whose main aim is to alleviate the loneliness and social isolation of older people-for example, Age Concern run a "Friendly Visitor" scheme.

Transport-Many older people are unable to use public transport as a result of age, disability, or ill health. Some voluntary organisations such as the WRVS, British Red Cross, St John Ambulance, Help the Aged, and Age Concern have wheelchair accessible transport to take members on outings and to and from day centres or hospital. A minimal fee to cover petrol costs may be charged, and on occasions the organisations may actually hire out their vehicles. Some organisations have a pool of volunteer drivers who use their own cars to transport older people to and from their destinations. In certain areas the British Red Cross and St John Ambulance are able to provide an ambulance with an escort for a minimal fee to cover

\section{Useful addresses}

Holiday Care Service, 2nd Floor, Imperial Buildings, Victoria Road, Horley, Surrey RH6 7PZ (tel 01293 774535)

WRVS National Office, 234-244 Stockwell Road, London SW9 9SP (tel 01714160146 ) 
costs-this varies from area to area. Dial-a-ride runs a door to door bus service for the benefit of older people and anyone with a disability; its vehicles are also available for community groups.

Holiday schemes-Information about holidays for older and disabled people can be obtained from the Holiday Care Service free of charge. It can provide advice and possible suggestions for people with special needs but does not actually arrange or book the holidays. Several charities organise their own holidays, some for more active older people and others for more frail or disabled people. Some charities have their own suitably adapted holiday homes or hotels; others (Age Concern, the RNIB, the RNID, Arthritis Care, Parkinson's Disease Society) organise group holidays for those of similar interests. Some charities may give grants towards holidays, and information on all these points can be obtained from the Holiday Care Service or the voluntary organisation in question.

Housing associations are non-profit making bodies, run by voluntary committees, providing housing and associated amenities, such as wardens, provision of meals, or homecare. Examples include national schemes such as Anchor Housing, Chantry Housing, and Help the Aged Housing Association. There are also local schemes and schemes aimed at particular groups, such as the British Legion Housing Association.

Hospices-Services provided through the hospice movement include

- Inpatient units providing symptom control, respite care, and continuing care for terminally ill patients

- Homecare services and domiciliary nursing services to provide assistance for patients and carers in their own homes

- A bereavement service for relatives and families.

Referral to the hospice is usually made by the hospital or general practitioner.

\section{The private sector}

In the 1980 s the private sector rapidly grew to become the main supplier of nursing homes and residential care. After the Community Care Act was implemented in 1993, this growth slowed down, and the focus has changed to provide more services for those wishing to remain in their own homes. A wide range of services can be available through the private sector, but for a person to be funded by the social services department, the provision of such services is subject to an assessment of need and an assessment of financial resources. ${ }^{2}$ Anyone may purchase these services using their own finances, but this can be prohibitively expensive. All nursing homes and some residential homes are privately owned. If a person is eligible for community care funding, the social services will provide a set amount towards the cost. This may or may not cover complete costs, depending on the particular home.

The private sector can also provide:

- Homecare services to provide help with tasks such as cooking, cleaning, washing, dressing and shopping

- A "night sleeper" service for those who need reassurance or supervision overnight;

- Live-in companions, to provide constant care and comfort on a long or short term basis

- 24 hour helplines - in the event of an emergency such as a fall, a press on the alert button on the telephone or on a pendant or bracelet alarm results in an immediate response from trained staff at a central control centre (some social services departments also provide this service)

- Domiciliary nursing services-trained nursing supervision can be provided up to 24 hours a day and 365 days a year. This may be more expensive than care in a nursing home, so if the person is funded by social services his or her choice may be overridden by financial considerations.

The telephone numbers of the private organisations providing these services can be obtained from the Yellow Pages under headings such as Nurses' agencies and care agencies, Nursing homes, and Disabledinformation and equipment. Social workers may also be able to provide detailed information on this subject.

1 Travers A. Caring for older people: carers. BMF 1996;313:482-6. 2. Wanklyn T. Caring for older people: homes and housing for elderly people. BMF 1996;313:218-21.

\section{More on the Jenner statue}

Fohn Empson (11 May, p 1210, "Fenner: full recognition at last") drew our attention to the BMF's outrage in 1858 at the proposal to demote Fenner from a place in Trafalgar Square, below is an extract from the leading article.

\section{WHERE SHALL WE PUT THE STATUE} OF JENNER

We wonder what the foreign subscribers to the Jenner Testimonial will think of the questions asked in Parliament with reference to the placing of the statue of the discoverer of vaccination in Trafalgar Square. Will they not open their eyes with wonder and astonishment, at the spectacle of member after member of the House of Commons getting up and demanding the expulsion of the effigy of one of the most illustrious of Englishmen, and one of the greatest benefactors of mankind, from the place of honour in which it is already located ? Will they not sneer at the civilisation of these islanders, who think the statue of a Napier is polluted by such company-who so scornfully imply that the hero who triumphed over a loathsome disease is not worthy to sit at the feet of the hero of Scinde?
"Cow-pox," said the member for Finsbury, "was a very good thing in its proper place, but it had no business amongst the naval and military heroes of the country. Everybody who heard of this statue spoke of it with ridicule and disgust; and if the Government should not feel justified in stopping the work, he trusted that the House would pass a resolution calling upon them not to pollute and desecrate the ground by erecting a statue there to the promulgator of cow-pox throughout the country."

We see no reason whatever that the finest site in Europe should be appropriated to the effigies of soldiers only. Why should those who destroy be ever placed in the front rank, whilst the philanthropist and the philosopher are only permitted to occupy out-of-the-way corners in forgotten squares, from which the living tide of man has long since ebbed? We are told that Lincoln's Inn Fields would satisfy the claims of Jenner; but if the publicity of the situation of an effigy should be measured by the universality of the benefit the original has conferred on mankind, we say emphatically that no statue that is or can be placed [in] Trafalgar Square could for one minute compare with that of the illustrious discoverer of vaccination.

(BMF 1858;i:395.) 